\title{
Pintura e histeria: lógica da sensação e figuras não representativas em Bacon e Deleuze
}

\author{
Cintia Vieira da Silva \\ cintiavs@hotmail.com \\ Universidade Federal de Ouro Preto (UFOP), Ouro Preto, Brasil
}

\begin{abstract}
0 artigo procura mostrar alguns elementos da análise deleuziana da pintura de Francis Bacon, concentrando-se nos aspectos que permitem considerar tal pintura como visceralmente antirrepresentativa. A pintura de Bacon figura sensações, promovendo, ao mesmo tempo, a experimentação e novas corporeidades por meio dessa produção figural. Pensando as relações entre os corpos e as forças que atuam sobre eles, provocando as ondas sensoriais, Deleuze concebe a pintura em geral, e a de Bacon em particular, como paradoxal experiência histérica do pensamento, experiência em que corpo e pensamento encontramse maximamente articulados.
\end{abstract}

parole chiave Deleuze; Bacon; figura; sensação; histeria; corpo

O livro de Deleuze dedicado à pintura de Francis Bacon tem o provocativo título de Lógica da sensação. A expressão, cunhada por Cézanne, parece ter sido escolhida por Deleuze para situar suas análises no interior de um amplo e antigo debate que perpassa a história da filosofia: sensível e inteligível têm uma relação de contraposição, de subordinação (do primeiro em relação ao segundo), de limitação recíproca, ou haveria uma maneira de pensar a sensação - filosoficamente, por conceitos, e artisticamente, por imagens ou figuras - tomando-a como evento deflagrador de modos de pensar não representativos? Ao se dedicar a um meticuloso estudo da pintura de Bacon, descrevendo os elementos que se repetem ou são retomados a cada tela, Deleuze acaba por reunir mais elementos para a teoria da sensação que vinha elaborando desde Diferença e repetição. O tema da 


\section{6}

intensidade e seu papel na sensação, que já aparecia neste livro publicado em 1968, é articulado à noção de corpo sem órgãos, conferindo mais densidade conceitual à corporeidade não orgânica em sintonia com um pensamento da diferença. Para iniciar a presente exposição desses conceitos, notadamente o de corpo sem órgãos, tal como expostos nos sete primeiros capítulos de Lógica do sentido, partiremos do comentário de Jaques Rancière em torno da relação entre Deleuze e as artes e da redefinição de estética promovida por Deleuze ${ }^{1}$.

Em seu artigo na coletânea Gilles Deleuze: uma vida filosófica, Jacques Rancière propõe uma questão que já é enunciada no título: Existe uma estética deleuzeana? Esclarecendo o teor de sua pergunta, Rancière diz que estética, em sua concepção, não constitui uma disciplina, uma parte da filosofia que se constituiria como teoria do belo, do gosto ou da arte (ou todas essas três coisas juntas). A estética seria mais um modo de pensar acerca das obras, tomado-as "como testemunhos de uma questão: uma questão que se refere ao sensível e à potência de pensamento que o habita antes do pensamento". Quando compreendemos estética desse modo, a filosofia deleuziana com seus modos "de descrição e de conceitualização" (RANCIÈRE. In: ALLIEZ, 1998, p. 505) pode ser considerada como eminentemente estética. Com efeito, tal modo de compreender a estética aproxima-se do projeto deleuziano, enunciado desde Diferença e repetição, de unir os dois sentidos tradicionais de estética: estética como teoria do belo e do sublime na arte e estética como estudo das condições de possibilidade da sensação e da percepção.

Mas Rancière não escolhe esse tema para estruturar seu artigo. $\mathrm{O}$ texto apresenta duas fórmulas deleuzianas a respeito da arte, fórmulas que parecem contraditórias, mas cuja coerência o artigo de Rancière tratará de mostrar. A primeira das formulações é extraída de O que é a filosofia?, texto escrito em parceria com Félix Guattari, e nos diz que: "A obra de arte é um ser de sensação e nada mais: ela existe em si [...] O artista cria blocos de perceptos e afectos, mas a única lei da criação é que o composto deve ficar de pé sozinho" (DELEUZE \& GUATTARI, 1997, pp. 213-14). A segunda fórmula, na verdade, é publicada dez anos antes da primeira, em Francis Bacon; Lógica da sensação. Parece-me que Rancière a coloca em segundo lugar, apesar de sua prioridade cronológica, por ela causar mais estranhamento que a primeira. Enquanto esta apresentava a obra de arte 
como um modo de ser específico, o que parece não se distanciar dos enunciados tradicionais da estética entendida como discurso sobre a arte, a segunda nos diz: "Com a pintura, a histeria se torna arte. Ou melhor: com o pintor, a histeria se torna pintura" (DELEUZE, 1981, p. 37). Temos, então, inicialmente, o contraste entre uma definição e um outro enunciado que coloca em jogo um devir, uma passagem, qual seja, de uma doença mental à obra de arte. Para explicar porque esse contraste ganha aparência de uma incompatibilidade, ou dentro de que contexto isso acontece, Rancière começa pela primeira fórmula, para depois aplica-la à obra de Bacon, pintor que constitui o tema do livro no qual a segunda fórmula é enunciada.

Assim, explicando a primeira fórmula, aparece a ideia da independência da obra de arte em relação a nós, ou seja, em relação ao público e ao artista. Uma vez criada, a obra se mantém sozinha, estando, evidentemente, pronta à apreciação de possíveis espectadores, sem, contudo, depender deles para seguir existindo e conservando sua potência. Nas palavras de Jacques Rancière:“A obra de arte assim o é na medida em quê se mantém por si só. Ela é o objeto que está diante de nós, que não tem necessidade de nós mas persiste, em virtude de sua própria lei de unidade de uma forma e de uma matéria, de partes e de sua junção". Sob essa definição, podemos colocar coisas tão díspares quanto uma tragédia, de acordo coma definição aristotélica, uma estátua grega, com a "calma idealidade" que lhe é conferida pela concepção hegeliana ou um romance como o de Flaubert, que parece não tratar de nada, mas "se mantém apenas pela força do estilo" (RANCIÈRE, 1998, p. 526). A maneira como Deleuze e Guattari definem a arte, além desse potencial de abarcar diferentes tipos de obra, tem ainda uma outra propriedade: um certo caráter dêitico. Como se a definição apontasse para a obra e mostrasse o que há nela.

O livro em que aparece a segunda fórmula começa justamente por uma descrição, mostra-nos ou nos chama a atenção para o que encontramos nos quadros de Bacon. Deleuze descreve uma determinada composição constante na obra de Bacon, ou melhor, uma composição que caracteriza essa obra, que produz certos efeitos e lida com certos problemas, suscitando outros ainda. Que composição é esta? Ela é formada por uma figura, que, muito frequentemente, está sentada. Em torno da figura, há um círculo e em torno do círculo, uma camada de tinta de cor viva que faz as vezes de fundo da tela. 


\section{8}

"Um círculo delimita frequentemente o lugar no qual está sentado o personagem, ou seja, a Figura" (DELEUZE, 1981, p. 9). É assim que Deleuze começa seu livro em torno da pintura de Francis Bacon. Trata-se, em primeiro lugar, de um trabalho de observação: o que vemos nas telas de Bacon? Como elas são compostas? Que procedimentos são utilizados por Bacon e a que servem tais procedimentos? Essas parecem ser as perguntas de que parte a investigação de Deleuze. Podemos considerar tais perguntas como precursoras da própria definição de arte enunciada em O que é a filosofia? Vimos que a arte, para Deleuze e Guattari, é aquilo que tem, por excelência, um poder de conservar. Conservar o que? Os blocos de sensações que cria de acordo com uma determinada composição de materiais e forças, materiais que variam de acordo com a obra em questão (uma tela, um romance, um filme e assim por diante). Para ser efetivamente uma obra de arte, um tal composto, um tal bloco de sensações deve ser capaz de se sustentar por si mesmo, o que significa que deve ser capaz de se conservar como bloco de sensações, mas implica igualmente na invenção de procedimentos que criam uma consistência entre os elementos ligados no composto e que sirvam à invenção de afectos e perceptos, ou seja, novas maneiras de perceber e de sentir que ultrapassam o percebido e o sentido, ou seja, a dimensão subjetiva da percepção e da afecção. A criação é, portanto, um aspecto definidor da arte, na perspectiva deleuzeana, mas não é prerrogativa do fazer artístico. Pensar é criar, seja em que domínio for (arte, ciência ou filosofia).

Assim, ao se voltar para a obra de Bacon, Deleuze procura detectar os procedimentos pictóricos que permitem que ela se mantenha de pé sozinha, para retomar a expressão utilizada em $O$ que é a filosofia?, e que ela nos apresente novos afectos e perceptos. O primeiro desses procedimentos é a colocação das Figuras num espaço contornado por um círculo, criando uma espécie de picadeiro de circo na tela. Qual o efeito de tal procedimento? Isolar a Figura (Ilustração 10, p.214). Mas esse isolamento pode ser conseguido por outros meios: "colocar a Figura num cubo, ou, antes, num paralelepípedo de vidro ou de gelo; colá-la sobre um trilho, sobre uma barra, como sobre o arco magnético de um círculo infinito; combinar todos esses meios, o ć́rculo, o cubo e a barra, como nessas poltronas arcadas que vão se alargando de Bacon" (DELEUZE, 1981, p. 9). Seja qual for o procedimento isolante utilizado, é preciso que ele não 
obrigue a Figura a ficar imóvel. O isolamento deve "tornar sensível uma espécie de encaminhamento, a exploração da Figura no lugar, ou sobre ela mesma." (DELEUZE, 1981, p. 9). O lugar definido pelo círculo e a Figura colocada nesse lugar entram numa relação que define um "fato", aquilo que tem lugar ali, que se passa naquele lugar ou entre o lugar e a Figura. Nesse isolamento, a Figura acaba por se tornar uma Imagem ou ícone bizantino (figura religiosa pintada num painel de madeira).

O próprio quadro já é uma "realidade isolada (um fato)" (DELEUZE, 1981, p. 9), pois os limites da tela e a moldura agem como isolantes. Os trípticos, que constituem um formato tão apreciado por Bacon e constituído por três telas ou painéis que não podem ser unidos num mesmo quadro ou moldura, mas devem ser apresentados juntos, também carregam a marca do isolamento, na medida em que são compostos de três telas distintas, isoladas. Mas a que serve todo esse cuidado em isolar? Por que ao isolamento da própria tela, de cada tela dentro de um tríptico ainda se deve acrescentar o isolamento da Figura na tela? Para impedir que a Figura se torne personagem de uma história, por mais rudimentar que seja. Bacon se engaja na busca de uma pintura que não parte de um modelo a ser representado e nem de uma história a ser contada. Sua busca é por uma Figura, que não seja nem narrativa, nem ilustrativa e nem figurativa, ou seja, como figura que valha por si mesma, que não represente outra coisa. Para escapar à representação, a pintura pode caminhar "em direção à forma pura, por abstração", ou então, como faz Bacon, perseguir “o puro figural, por extração ou isolamento" (DELEUZE, 1981, p. 9). O isolamento é o primeiro passo para compor uma Figura não figurativa, uma figura que se mantenha sem representar outra coisa.

Como o isolamento atua nesse sentido? É que, no uso figurativo das imagens, além da relação da imagem com o objeto que ela ilustra, há a relação de uma imagem com outras. Essa segunda relação, entre imagens, é que forma "um conjunto composto de imagens" (DELEUZE, 1981, p. 10) que assinala o objeto a ser representado por cada uma delas. Ao caráter ilustrativo da imagem na representação corresponde uma narratividade entre as figuras. Figuras colocadas em contato dão margem ao aparecimento de uma história, por isso, o isolamento é necessário, para bloquear a narratividade que poderia surgir da figura. Mas não basta o isolamento para romper com a representação, veremos que há outros procedimentos 
que atuam neste sentido.Veremos também que o isolamento não impede que haja um outro tipo de relação entre as Figuras, como nos trípticos, por exemplo, um tipo de relação que não é narrativa, que não se refere a uma comunidade de objetos ou ideias representados, mas à participação num mesmo fato (lembremos que fato, para Bacon, é aquilo que se passa no quadro, entre seus elementos).

Falaremos mais detalhadamente dessa relação mais tarde. Por ora, vamos continuar acompanhando a descrição dos elementos que compõem os quadros de Bacon.Vimos que há pelo menos uma Figura, isolada num círculo ou paralelepípedo, sobre um picadeiro, uma cadeira, uma cama ou poltrona. Este conjunto não ocupa toda a tela. Deleuze descreve uma certa evolução na obra de Bacon no que diz respeito à ocupação desse "resto" da tela.Tal evolução se faria no sentido de procurar uma alternativa às formas da paisagem, que pertence ao registro do figurativo; ao fundo de onde surge a forma; ao claro-escuro, composto por um espessamento da cor que ocasiona um jogo de sombras; ou ainda à textura, que ocasiona uma variação. Assim, num quadro de 1957, há um conjunto Figurapaisagem; num outro, intitulado Figura numa paisagem, de 1945 (Ilustração 11, p.215), aparecem "texturas extremamente nuançadas", como é o caso também de Figura estudo I, do mesmo ano (Ilustração 12, p.216). Também encontramos o trabalho com "espessuras e densidades" (DELEUZE, 1981, p. 11), do qual a Cabeça II, de 1949, seria um bom exemplo. Há também um período em que a pintura de Bacon parece dominada por um espaço sombrio que envolve as figuras.

Mas nada disso constitui, aos olhos de Deleuze, a contribuição própria de Bacon à pintura. Assim, as paisagens de Bacon antecipam os "traços a-significantes" que virão a compor seus quadros mais tarde, por isso são geralmente compostas de grama (e não de árvores, arbustos ou pedras, por exemplo, que viriam a constituir outras figuras). De maneira semelhante, o uso de texturas, sejam elas compostas por espessamento da cor, por sombras ou pelo caráter vago dos contornos, antecipa "o grande procedimento de limpeza local, com lenço, vassourinha ou escova”. Tal procedimento permite o surgimento de uma "zona não figurativa" sobre a qual se estende a espessura. $\mathrm{Na}$ verdade, o mais característico da pintura de Bacon é que o restante da tela seja ocupado por uma camada lisa de tinta de uma só cor viva. Essa camada de tinta é feita de modo a envolver 
a figura. Não há distância que viria a criar uma ideia de perspectiva entre elas. A Figura, que funciona como forma, e a camada de tinta, que funciona como fundo,estão num mesmo plano, num mesmo espaço plano que poderíamos chamar de tátil ou háptico, porque instaura uma relação direta entre a visão e o tato. $\mathrm{O}$ círculo que contorna a figura assegura a correlação entre ela e a camada de tinta, pois lhes serve de "limite comum" (DELEUZE, 1981, p. 11).

Numa entrevista a David Sylvester, Bacon também descreve seu trabalho usando três elementos, mas estabelece uma relação de suas imagens com a escultura.

"Pensando nessas imagens como esculturas, de repente me ocorreu que poderia fazê-las através da pintura, e de um jeito muito melhor em pintura, seria uma espécie de pintura estruturada cujas imagens, por assim dizer, se ergueriam de um rio de carne. Está parecendo uma ideia incrivelmente romântica, mas eu vejo tudo muito formalmente - E qual seria a forma? - As figuras evidentemente estariam erguidas sobre estruturas - Várias figuras? - É, e provavelmente haveria uma calçada acima do ambiente natural, de onde elas poderiam erguer-se, como se brotando de poças de carne, se possível, na forma de imagens daquele tipo de gente que normalmente se vê pelas ruas. Espero conseguir fazer figuras que pareçam surgir da própria carne com seus guarda-chuvas e seus chapéus coco, e fazer delas figuras tão lancinantes quanto uma imagem de crucificação" (SYLVESTER, 2007, p. 83).

Mais à frente, Bacon, completa: "Quando penso numa escultura, é com ela apoiada sobre uma espécie de suporte, um enorme suporte que permita às esculturas deslizar ao longo dele e às pessoas modificar a posição das peças como bem entenderem" (SYLVESTER, 2007, p. 108). Nesse sentido, o círculo que envolve a Figura seria como o pedestal de uma escultura e a camada de tinta seria sua estrutura.

A proximidade entre esses dois setores, a camada de tinta que serve de fundo e a Figura, que ocupa o lugar da forma, proximidade que não é, contudo, uma indistinção, pois eles estão separados pelo círculo, que "constitui um espaço absolutamente fechado e giratório" (DELEUZE, 1981, p. 12) com bastante eficácia. Tal eficácia é justamente dada pela precisão, pela nitidez dos contornos. A nitidez é de tal modo parte integrante 
da pintura de Bacon que até mesmo o vago, o fluido, é obtido pela operação de levar a nitidez ao paroxismo. $\mathrm{O}$ círculo, como contorno, que às vezes pode ser oval também, tem um papel importante nessa precisão, na definição dos limites entre a Figura e a superfície a que ela se acopla. Contudo, ao mesmo tempo em que ela serve de limite entre os dois setores do quadro, o círculo intermédia um contato entre ambos, por isso Deleuze diz que ele "é como uma membrana percorrida por uma dupla troca”. Ainda que não haja uma história narrada pela pintura, algo se passa nela e o que se passa é justamente a troca de mão dupla entre a Figura e o fundo, entre o fundo e a Figura (nesse sentido é que a cor do círculo coloca um problema, na medida em que ele é intermediário entre os dois setores). Muitas vezes as Figuras parecem esperar o que vai acontecer, mas isso não faz delas espectadores de uma representação, mas, antes, testemunhos, elementos capazes de atestar uma variação, funcionando como constantes a partir das quais ela se torna perceptível (sobretudo nos casos em que há mais de uma figura). Deleuze fala de um "esforço para eliminar o espectador" nos quadros de Bacon, o que pode ser mais bem apreciado se compararmos as duas versões da tauromaquia, de 1969. De uma versão à outra, vemos o desmoronamento do caráter espetacular da tourada e a destituição da multidão do papel de espectador. Além disso, a última versão consegue reunir touro e toureador num "fato único ou comum" (DELEUZE, 1981, p. 15).

A esse esvaziamento da função de espectador corresponde uma transformação da ideia de espetáculo: o que há para ser visto é apenas a própria "espera ou esforço" da Figura, mas tais visões só são produzidas "quando não há mais espectadores". O esforço da Figura, além de corresponder a uma tentativa de eliminar o espectador, dá mostras de um "atletismo derrisório", à maneira de alguns personagens de Kafka, como "o grande Nadador que não sabia nadar" ou o "artista da fome". O ápice desse atletismo em Bacon é Pintura, de 1978, em que uma "Figura estende todo seu corpo, e uma perna, para fazer girar a chave da porta com seu pé, do outro lado do quadro" (DELEUZE, 1981, pp. 15-16). Um tal atletismo é tanto mais impressionante quanto mais percebemos que há um movimento que não começa na Figura, mas na camada de tinta que é a estrutura material do quadro, camada que é arrastada por um movimento que a faz enrolar-se por vezes na forma de um cilindro e obriga a Figura a acompanhá-lo. 
Há ainda um outro movimento, que nasce da Figura, na medida em que ela é um corpo que tenta escapar, escorrer para fora de si mesmo (e não uma pessoa que tenta fugir do próprio corpo). Podemos observar com nitidez um tal movimento em Figura no lavabo, de 1976, em que "um corpo-figura faz sobre si mesmo um esforço intenso imóvel, para escapar inteiro pelo ralo". As figuras de Bacon são corpos que se esvaem em direção à camada de tinta, corpos que lutam para escapar num espasmo, tentando sair por um de seus órgãos, ou num grito. A intensidade da presença das sombras na pintura de Bacon, que se equipara à dos corpos, é consequência do fato de que as sombras são algo "que escapou em tal ou qual ponto localizado no contorno" (DELEUZE, 1981, pp. 16-17). Esse segundo tipo de movimento determina uma outra configuração do contorno. Empurrado pelo movimento da Figura em direção à estrutura material, o contorno deixa de ser plano para formar um volume oco, dotado de um ponto de fuga para o qual tende o corpo no quadro. Tanto a pia do quadro de que já falamos quanto os guarda-chuvas de Bacon têm essa função de volume. $\mathrm{O}$ círculo, então, assume a forma de pia ou de guarda-chuva, adquirindo volume. De maneira semelhante, "o cubo ou o paralelepípedo" (DELEUZE, 1981, P. 17) se transformam em espelho. Os espelhos de Bacon não são superfícies que refletem, mas que deformam a figura, que esticam ou contraem seu corpo no movimento em direção à estrutura material, passando por instrumentos como os guarda-chuvas, pias ou seringas que funcionam como órgãos-prótese.

Já dissemos que a Figura é corpo. Pois bem, isto se traduz numa ausência de rosto nas figuras de Bacon. Bacon pinta as cabeças de suas Figuras, e mesmo seus retratos são retratos de cabeças, não de rostos. O rosto se define por um determinado regime de signos, ele é "uma organização espacial estruturada que recobre a cabeça". O rosto se inscreve sobre o corpo, ao passo que a cabeça pertence ao corpo, ela "é uma dependência do corpo, ainda que ela seja a ponta dele". Os retratos de Bacon têm como projeto "desfazer o rosto, reencontrar ou fazer surgir a cabeça sob o rosto", como manifestação de um certo espírito do corpo, "sopro corporal e vital, um espírito animal". Essa animalidade que se manifesta na cabeça contamina também o restante do corpo, ela é em parte responsável pelas deformações sofridas pelo corpo. Mas não se trata de uma analogia entre formas ou da passagem de uma forma a outra (do homem ao animal). 


\section{4}

Trata-se da criação de uma zona em que não se pode mais distinguir o homem do animal. Esse processo começa com os traços de animalidade que surgem na cabeça. É o que Deleuze e Guattari, já em Mil platôs, lançado em 1980, um ano antes de Lógica da sensação, portanto, chamam de devir-animal. O devir é um bloco que captura o homem e o animal, em que o homem se apropria de afectos do animal, ao mesmo tempo em que o animal se torna outra coisa. No caos dos devires-animal deflagrados pelas cabeças que Bacon pinta, "o homem se torna animal, mas ele não se torna animal sem que, ao mesmo tempo, o animal se torne espírito, [...] espírito físico do homem". Para Deleuze, toda Figura de Bacon, por maior que seja seu isolamento, está sempre "acoplada”, já que tomada por um devir-animal, exprimindo "o fato comum do homem e do animal" (DELEUZE, 1981, pp. 19-20).

Mas que fato é esse? Em primeiro lugar, o que estabelece a comunidade, ou a zona de indiscernibilidade, entre homem e animal é o corpo enquanto carne. Gostaria de chamar a atenção aqui para o fato de que o francês tem duas palavras para carne: chair e viande. Chair é a carne viva e é também usada em sentido metafórico, a carne como sede dos prazeres, dos sofrimentos e assim por diante. Já viande é a carne da qual nos alimentamos, a carne animal, numa palavra: a carne morta. Deleuze começa falando que a zona em que homem e animal entram num devir comum é tornada possível pela carne enquanto chair, carne viva, carne que constitui o "material corporal da Figura" e que recobre a estrutura formada pelos ossos. Nesse sentido, a dualidade entre carne e ossos faz parte do atletismo das Figuras de Bacon: "os ossos são como os aparelhos de ginástica em que a carne é a acrobata” (DELEUZE, 1981, p. 20). Daí o interesse de Bacon pelas crucificações: elas possibilitam posturas em que a carne se revela, posturas em queda (veremos mais adiante a importância da queda para Bacon). A crucificação é o evento privilegiado da transformação da chair em viande. Mas a viande não é mais uma carne morta, ela é a carne que "manteve todos os sofrimentos e tomou para si todas as cores da carne viva” (DELEUZE, 1981, p. 20). E é justamente a carne como viande, a carne animal, que constitui o fato comum entre homem e animal. $\mathrm{O}$ horror e a piedade na pintura de Bacon não se dirigem aos animais, mais à carne animal (viande) que sofre, porque "todo homem que sofre é um pedaço de carne [de la viande]” (DELEUZE, 1981, p. 21). 
Bacon estabelece uma estranha aliança, mais ainda, uma estranha identidade entre a carne pendurada no açougue e o corpo crucificado, o que faz Deleuze dizer que "é apenas nos açougues que Bacon é um pintor religioso" (DELEUZE, 1981, p. 21) 2. Segundo o testemunho do próprio Bacon: "sempre me tocaram muito os quadros que mostram matadouros e carnes, e para mim elas fazem parte de todo esse negócio da crucificação" (SYLVESTER, 2007, p. 23). Mais adiante: "bem, claro, nós somos carne, somos carcaça em potencial. Sempre que entro num açougue, penso que é surpreendente eu não estar ali no lugar do animal" (SYLVESTER, 2007, p. 46). Mais do que uma simpatia ou compaixão pelos animais, do que uma "identificação sentimental", a pintura de Bacon estabelece uma "identidade de fundo" entre o homem e o animal quando ambos estão em sofrimento: "o homem que sofre é um bicho, o bicho que sofre é um homem” (DELEUZE, 1981, p. 21). Para Deleuze, a cabeça concentra a carnalidade e a animalidade do corpo das Figuras de Bacon, ela é o centro irradiador dos devires-animal que povoam suas telas. As cabeças de Bacon são, antes de mais nada, carne, muito mais do que ossos (contrariamente ao que ocorre nas obras de outros pintores, como El Greco, por exemplo).

A cabeça da Figura, vista como bloco de carne, é a ponta de um devir-animal que arrasta o resto do corpo, que tende a escapar em direção à estrutura material do quadro. Nesse movimento, a tendência que está em jogo não é apenas a aquisição, por parte do homem, de potências animais, mas a própria dissolução da Figura, a tendência da pintura a se tornar pura "Cor ou Luz", a construir "um espaço que não seria mais que Saara" (DELEUZE, 1981, p. 23), fazer um retrato com "as escalas do Saara” (SYLVESTER, 2007, p. 56), como diz Bacon.

Deleuze vê a obra de Bacon como um processo de dissolução progressiva da Figura. Como vimos, essa dissolução começa com o escoamento do corpo por um de seus órgãos ou órgãos-prótese, através de espasmos, dos quais o grito é o caso mais emblemático. No grito, "todo o corpo escapa pela boca que grita", como sangue que jorra de uma veia aberta. $\mathrm{O}$ grito se prolonga em sorriso, supera-se em direção a um sorriso que funciona como mais um recurso para "o desvanecimento do corpo", como o sorriso do gato de Cheshire, na Alice de Lewis Carrol. Nesse sentido, Deleuze chama atenção para duas versões do homem com guarda-chuva e como o sorriso se torna mais pronunciado na segunda versão. Mais 
próximo ainda do sorriso do gato de Alice, que permanece visível após o desaparecimento do gato, estão "o sorriso gozador" na tela de 1954, um dos vários Papas pintados por Bacon, ou o do quadro de 1953, em que vemos um homem sentado que sorri. Esses sorrisos perturbadores, que causam a impressão de poderem sobreviver ao próprio desaparecimento da Figura, são qualificados por Bacon de histéricos. Esta sugestão é desenvolvida por Deleuze num sentido inusitado: a histeria qualificará não mais a Figura, ou aquele que serviu de modelo para o quadro. Ainda que Bacon diga que o "modelo" do retrato de 1953, da cabeça humana do mesmo ano e do Papa de 1955 era "muito neurótico, quase histérico" (SYLVESTER, 2007, p. 48), há uma outra histeria, mais importante, que é a da própria pintura.

Estamos nos aproximando da segunda fórmula envolvendo a concepção deleuzeana de arte que vimos no começo, acompanhando o artigo de Jacques Rancière. Antes de chegarmos a ela, passemos pela definição de histeria que se encontra no dicionário. Se formos ao Aurélio, encontraremos que histeria é uma "afecção mental cujos sintomas se baseiam em conversão" de emoções em manifestações físicas, "e caracterizada por falta de controle sobre atos e emoções, ansiedade, sentido mórbido de autoconsciência, exagero do efeito de impressões sensoriais, e por simulação de diversas doenças". Dessa definição, há dois aspectos que podem nos guiar na compreensão da associação que Deleuze faz entre pintura e histeria, motivada principalmente pela obra de Bacon. Um primeiro aspecto é justamente a conversão, esse mecanismo potencialmente patológico em que afecções ou emoções se manifestam no corpo. Tudo na histeria passa pelo corpo, manifesta-se no corpo, ganha corpo e, na medida em que a obra de Bacon confere uma centralidade ao corpo humano, poderia encontrar-se com a histeria. Um segundo aspecto é a hipersensibilidade, o superdimensionamento do sensorial. Ora, em Lógica da sensação, Deleuze detecta um modo de fazer arte, especialmente em música e em pintura, que rompe com a representação para buscar a sensação. Vimos que na definição de $O$ que é a filosofia? a centralidade da sensação era estendida a todas as artes e a todos os estilos. Arte, em geral, é definida nesse livro de 1991 como aquilo que produz seres de sensação. Pois bem, Logique de la sensation foi publicado em 1981. O que nesse texto era visto como um estilo ou modo de fazer arte será encarado, dez anos mais tarde, como um 
dado essencial de toda e qualquer arte, como um traço definidor dela. A via da sensação deixa de ser vista como um dos caminhos possíveis para o fazer artístico e passa a ser seu objetivo.

Mas, na formulação que nos ocupa agora, ou seja, na sexta rubrica ou capítulo de Logique de la sensation, que se chama "Peinture et sensation", Deleuze introduz o tema do tratamento da sensação na pintura de Bacon através de uma aproximação com Cézanne. Retomando a ideia de que há duas maneiras para "ultrapassar a figuração" em pintura, uma pela abstração e a outra que busca a Figura, Deleuze nos diz que esta segunda via é chamada por Cézanne de sensação. Uma vez liberada das tarefas de contar uma história e de representar um objeto, a Figura se torna "a forma do sensível relacionada à sensação; ela age diretamente sobre o sistema nervoso, que é carne". Mas esta forma encarnada pela Figura se distingue da Forma abstrata, que "age por intermédio do cérebro, mais próximo do osso." Cézanne foi o pintor que conferiu à via da sensação "um estatuto sem precedente" (DELEUZE, 1981, p. 27), consolidando a busca pela captura da sensação na pintura, sensação que não se confunde nem com o clichê, nem com o espontâneo, nem como sensacional ou espetacular.

Por outro lado, a sensação exprime o encontro do sujeito e do objeto, não podendo se confundir com nenhum dos dois de maneira isolada e tendo sempre as duas dimensões, subjetiva e objetiva, necessariamente presentes. A sensação exprime "a unidade do sentente 3 e do sentido", a tal ponto que, "no limite, é o mesmo corpo que a dá e que a recebe, que é ao mesmo tempo sujeito e objeto", porque só temos acesso à sensação captada num quadro entrando nele, encarnado-a por nossa conta. Nesse sentido, Cézanne suplanta os impressionistas ao negar que a sensação possa ser produzida ou captada pelo “jogo 'livre' ou desencarnado da luz e da cor" e sustentar que ela está nos corpos, assim como a cor, mesmo que seja na singeleza do corpo de uma maçã. Pintar os corpos é pintar a sensação na medida em que não se pinta um corpo "representado como objeto", mas sim "vivido como experimentando tal sensação" (DELEUZE, 1981, p. 27). Esse projeto de pintar a sensação é justamente o que aproxima Bacon de Cézanne e essa proximidade pode ser sentida até no vocabulário de ambos. Bacon fala em "registrar o fato" (DELEUZE, 1981, p. 28), que Cézanne colocava no polo objetivo da sensação, deixando o instinto e o temperamento no polo subjetivo. 
Semelhante aproximação pode parecer estranha se nos ativermos a uma certa dimensão da obra dos dois pintores: o que poderia haver de comum entre as paisagens e naturezas mortas de Cézanne e os corpos em deformação de Bacon? Se os temas são diferentes, o projeto é muito semelhante. Para os dois pintores, trata-se de pintar a sensação de modo que ela atinja diretamente o sistema nervoso, sem passar pelo cérebro, ou seja, sem mediação intelectual. Daí vem a insatisfação em relação tanto à pintura figurativa quanto à abstrata, ambas só produzem a sensação mediada por uma história ou por uma Forma a serem apreendidas intelectualmente, para, em seguida, restituir ao apreciador do quadro uma sensação. Bacon partilha com Cézanne da busca por uma Figura como forma da sensação, por um figural não representativo (vale dizer, não figurativo). Mas essa é uma definição negativa do projeto pictórico de Bacon. Positivamente, a sensação é definida como "o que passa de uma 'ordem' a outra, de um 'nível' a outro, de um 'domínio' a outro" do sensível. Por isso, por se dar na passagem, a sensação é "agente de deformações do corpo". O abstracionismo e o figurativismo permanecem insuficientes por se limitarem a "um só e mesmo nível" da sensação, operando apenas "transformações da forma" sem alcançar as "deformações do corpo" (DELEUZE, 1981, p. 28).

Essas passagens de nível não constituem apenas séries em que cada sensação é um termo, como poderíamos ser levados a supor pelo próprio fato de que a obra de Bacon é toda atravessada por séries:"série das crucificações, série do papa, série de retratos de autorretratos, série da boca, da boca que grita, da boca que sorri...” (DELEUZE, 1981, p. 28). Mas não se trata apenas disso, os diferentes níveis ou ordens já estão numa mesma sensação, a sensação envolve "uma diferença de nível constitutiva, uma pluralidade de domínios constituintes”, ela é eminentemente sintética. Se a Figura pode captar a sensação, é por acumulação, coagulação. Mas, se a sensação é sintética, se ela é uma síntese entre diferentes níveis, dos quais ela constitui uma "unidade sentente e sentida" (DELEUZE, 1981, p. 29), em que repousa essa unidade?

Já podemos antecipar que tal unidade não pode ser procurada no "objeto representado" ou na "coisa figurada" (DELEUZE, 1981, p. 29), já que a pintura de Bacon busca justamente instituir uma função não representativa para a Figura. Evidentemente, mesmo esta via que busca escapar da 
representação tem uma dimensão figurativa, mas ela não é a essencial. $\mathrm{O}$ esforço para captar num quadro a violência da sensação, produzir uma obra capaz de provocar essa violência, determina um distanciamento cada vez maior em relação ao 'sensacional'. Dizendo de outro modo, Bacon tem em vista a eliminação progressiva da "figuração primária do que provoca uma sensação violenta” (DELEUZE, 1981, p. 29). A colocação do problema da composição da Figura nesses termos permite compreender melhor esta frase tão característica de Bacon: "eu quis pintar mais o grito do que o horror” (SYLVESTER, 2007, p. 48). Mais uma vez, isso quer dizer: pintar a sensação, captá-la com meios pictóricos, e não representar aquilo que a provoca. Voltando ao quadro do papa, Deleuze lembra que nada de horrível é figurado ali, o que fica ainda mais patente no uso que Bacon faz da cortina que coloca diante da Figura. Ela não serve apenas para isolar o papa, mas também "a maneira pela qual ele mesmo não vê nada, e grita diante do invisível" (DELEUZE, 1981, p. 29). Assim, ao evitar mostrar o horror, Bacon faz com que possamos senti-lo de maneira mais intensa. Como na crueldade de Artaud, o que se busca é a intensidade da sensação, essa é a violência presente na pintura de Bacon, não a violência de uma história que se conta ou de um objeto que se representa.

Outra hipótese a ser descartada é a de que a os níveis da sensação seriam estabelecidos por sentimentos ambivalentes. Em um primeiro momento, tal hipótese restringe a sensação ao "espectador que olha o quadro", na medida em que ele experimentaria sentimentos ambivalentes diante da tela, como atração e repulsa, amor e ódio, e assim por diante. Mas a situação não melhora se pensarmos numa ambivalência de sentimentos da própria Figura, pois, nesse caso, estaríamos supondo "que a Figura experimentaria" sentimentos "em relação a coisas representadas" ou "a uma história contada". Ao invés de sentimentos, Bacon lida com a correlação entre sensação e instinto, a partir da qual "a sensação é o que determina o instinto em tal momento, assim como o instinto é a passagem de uma sensação a outra" numa procura pela sensação "que preenche a carne em tal momento de sua decida, de sua contração ou dilatação" (DELEUZE, 1981, p. 30).

Em seguida, Deleuze fala de uma interpretação para o caráter sintético da sensação que ele julga mais interessante. Tal interpretação estabelece uma ligação entre sensação e movimento, concebendo os diferentes 
"níveis de sensação" como "paradas ou instantâneos do movimento, que recomporiam o movimento sinteticamente", restituindo sua "continuidade, sua velocidade, sua violência" (DELEUZE, 1981, p. 30). Efetivamente, há na obra de Bacon casos de "movimentos violentos", mas, no mais das vezes, suas Figuras realizam pequenos passeios exploratórios, em que o deslocamento é menos importante, pois é mais o contorno que envolve a figura que se desloca do que ela mesma. O movimento não é a preocupação central de Bacon, que tende a fazer dele um 'movimento no mesmo lugar", à maneira de um espasmo, o que aponta para o problema que lhe interessa mais de perto, ou seja, "a ação sobre o corpo de forças invisíveis" (DELEUZE, 1981, p. 31).A deformação dos corpos é causada justamente por essas forças.

De acordo, ainda, com uma outra hipótese, que Deleuze diz ser mais “"fenomenológica”, o caráter sintético da sensação repousaria numa espécie de sinestesia de fundo, numa "unidade original dos sentidos". Cada domínio ou nível da sensação seria constituído pelos diferentes "órgãos dos sentidos", mas cada sensação provinda de um dos sentidos remeteria aos outros sentidos, estabelecendo uma "comunicação existencial" entre as cores, os gostos, as texturas, os odores, os sons, os pesos, o que delinearia 'o momento ‘pático' (não representativo) da sensação”. O que garante essa comunicação entre os dados sensoriais de todas as proveniências, o que possibilita que o pintor nos faça ver essa "unidade original dos sentidos" é o fato de que cada sensação esteja ligada a "uma potência vital que ultrapassa todos os domínios e os atravessa”. O nome que Deleuze dá a essa potência é Ritmo, mas isso não significa que apenas a música possa manifestá-lo. O Ritmo se faz quadro ou música de acordo com o nível que investe preferencialmente, auditivo ou sonoro. O Ritmo é a contração e a dilatação, a diástole e a sístole, é "o mundo que me toma a mim mesmo se fechando sobre mim, o eu que se abre ao mundo, e o abre ele próprio" (DELEUZE, 1981, p. 31)4. Esse ritmo visual pulsa nas telas de Cézanne, manifestando-se como sensação visual. Parece que o mundo de Bacon com toda a sua artificialidade e seu fechamento, nas antípodas das paisagens e naturezas mortas de Cézanne, que constituem seu mundo pictórico como Natureza, também é perpassado por esse movimento vital que se traduz num Ritmo. O duplo movimento da camada de tinta que funciona como fundo em direção à Figura, tendendo a se enrolar sobre ela, e da 
Figura em direção à camada de tinta, encaminhado-se para se fundir nela retoma um tal Ritmo vital. Daí vem o otimismo de Bacon, como aposta nessa potência vital capaz de atingir diretamente nossos nervos, a despeito de todas as imagens horríveis que chegam a nosso cérebro, o que Deleuze sintetiza numa fórmula definidora de Bacon: "figurativamente pessimista, mas figuralmente otimista” (DELEUZE, 1981, p. 31) .

Para Deleuze, contudo, a hipótese "fenomenológica" ainda não é a última palavra a respeito do caráter sintético da sensação. É que o Ritmo, potência vital, "só pode ser descoberto ultrapassando o organismo", suplantando o "corpo vivido" para encontrar uma "Potência mais profunda e quase impossível de se viver". Tomando emprestado o termo criado por Artaud para nomear uma tal Potência, Deleuze a chama de corpo sem órgãos. Essa terminologia, contudo, presta-se a equívocos, na medida em que o que esse termo designa não é a ausência de órgãos ou a oposição entre o corpo e os órgãos, mas organização dos órgãos que faz deles um todo chamado de organismo. O conceito de corpo sem órgãos é objeto de longos desenvolvimentos em Mil platôs, livro que Deleuze escreveu em parceria com Félix Guattari um ano antes do texto a respeito de Bacon. Vamos nos ater, contudo, à definição de corpo sem órgãos que encontramos em Logique de la sensation. Em primeiro lugar, Deleuze nos diz que o corpo sem órgãos é um "corpo intenso, intensivo". Isto significa que ele não é apenas um corpo que ocupa lugar no espaço, ou seja, um corpo extensivo, mas é um corpo preenchido por graus de uma sensação, "percorrido por uma onda que traça no corpo níveis ou gradientes segundo as variações de sua amplitude" (DELEUZE, 1981, p. 33). Os órgãos funcionam, então, como esses níveis ou gradientes que vibram com a sensação, como no ovo, em que a repartição definitiva dos órgãos ainda não foi feita.

O corpo sem órgãos desfaz a organização do organismo para revelar "toda uma vida não orgânica". A sensação arrasta o corpo para esse regime de funcionamento chamado corpo sem órgãos, pois, ao atingir "o corpo através do organismo, ela rompe as barreiras da atividade orgânica", entranhando-se na carne como "onda nervosa” (DELEUZE, 1981, p. 33). Em função desse tema do corpo sem órgãos, podemos pensar numa aliança entre Bacon e Artaud, num encontro em torno de alguns elementos. Primeiramente, com relação às Figuras de Bacon, podemos dizer que elas 
são corpos sem órgãos, na medida em que desfazem "o organismo em proveito do corpo", dissolvem "o rosto em proveito da cabeça". Nesse encontro entre Artaud e Bacon, o corpo sem órgãos" se define como "carne e nervo, uma onda o percorre que traça níveis nele; a sensação é como o encontro da onda com Forças agindo sobre o corpo, 'atletismo afectivo', grito-sopro; quando ela é assim relacionada ao corpo, a sensação deixa de ser representativa" para se tornar "real; e a crueldade será cada vez menos ligada à representação de algo horrível, ela será somente a ação das forças sobre o corpo, ou a sensação (o contrário do sensacional)". A pintura de Bacon busca "o fato intensivo do corpo" nas suas Figuras-corpos sem órgãos. Os procedimentos pictóricos de limpeza com estopa escova em seus quadros neutralizam "partes do organismo", devolvendo-as "a seu estado de zonas ou de níveis" (DELEUZE, 1981, pp. 33-34).

Tínhamos adiantado a possibilidade de uma relação entre sensação e histeria, cristalizando-se na pintura. Ora, com a noção de corpo sem órgãos, tal relação se estabelece efetivamente. Deleuze se pergunta se a histeria não é "a realidade viva" do corpo sem órgãos, tendo em vista que há muitos tipos de abordagem do corpo sem órgãos (através do álcool, da droga, na esquizofrenia, no sadomasoquismo e assim por diante). Mas é como se houvesse um fundo histérico em todas essas diferentes manifestações de corpo sem órgãos. A "série completa” do corpo sem órgãos em conexão com a onda sensorial consegue explicar de modo satisfatório o caráter sintético da sensação, os diferentes níveis nela envolvidos. Segundo Deleuze, tal série é a "realidade histérica do corpo" (DELEUZE, 1981, pp. 34-35).Vejamos então em que consiste essa série.

Inicialmente, o corpo sem órgãos é como uma massa caótica em que nenhuma determinação se delineia. Então, "uma onda de amplitude variável percorre o corpo sem órgãos nele traçando "zonas e níveis" de acordo com "as variações de sua amplitude". Sob a ação de "forças exteriores" que se encontram com a onda num dado nível, surge uma sensação. Tal encontro determinará, assim, um órgão correspondente à sensação, mas não de modo definitivo, e sim de modo "provisório". A duração desse órgão é condicionada pela "passagem da onda" e pela "ação da força" (DELEUZE, 1981, pp. 33-34), assim como sua posição e deslocamento. Um pouco como nessa passagem do Almoço nu, de William Burrroughs, que Deleuze conecta com esse momento da série do corpo sem órgãos: 
“os órgãos perdem toda constância, quer se trate de sua localização ou de sua função... órgãos sexuais aparecem por todo lado... ânus emergem, abrem-se para defecar, depois se fecham... o organismo inteiro muda de textura e de cor, variações alotrópicas reguladas num décimo de segundo" (BURROUGHS, p. 21. APUD DELEUZE, 1981, p. 34). Nesse momento, então, "o corpo sem órgãos se define por um órgão indeterminado" e não pela ausência de órgãos. Assim, ele difere do organismo porque este "se define por órgãos determinados" (DELEUZE, 1981, pp. 34-35), ou seja, com funções estabelecidas e fixas. No corpo sem órgãos, há esse momento em que parece que apenas um órgão migra e cumpre funções diferentes de acordo com a passagem da onda que se encontra com as forças, ou seja, de acordo com a sensação. Novamente, Deleuze aciona a descrição de Burroughs: "no lugar de uma boca e de um ânus que correm o risco de se arruinar, por que não possuir um único orifício polivalente para a alimentação e a defecação? Poder-se-ia obstruir a boca e o nariz, entulhar o estômago e fazer um buraco de aeração diretamente nos pulmões, o que deveria ter sido feito desde a origem" (BURROUGHS, p. 146, apud DELEUZE, 1981, p. 35). Contudo, num segundo momento, nota-se que não se trata apenas de um órgão indeterminado e polivalente, mas de determinações que se esboçam e se desfazem para dar lugar a novas determinações. Para retomar o texto de Burroughs, não seria então um mesmo orifício que cumpriria as funções da boca e do ânus, mas uma boca surgiria, desapareceria, e, em seguida, veríamos o surgimento de um ânus e assim por diante, ainda que o intervalo entre o surgimento de um e o desaparecimento do outro fosse mínimo. Assim, a definição última do corpo sem órgãos, que completa a série, é a de que "órgãos determinados" se tornam presentes nele de maneira "temporária e provisória". Ora, se os órgãos determinados surgem e desaparecem, pintar esse movimento é um modo "de introduzir o tempo no quadro". A pintura dessas variações do corpo se efetua em termos de cores e de texturas, daí o tratamento tão diferenciado dos corpos em relação ao que funciona como fundo: à camada de tinta lisa e monocromática se opõe todo "um cronocromatismo do corpo". Ora, essas variações, essas migrações de órgãos, surgimento e desaparecimento de órgãos determinados é que explica o caráter sintético da sensação, apresentando-a como "diferença de nível” (DELEUZE, 1981, p. 35). Diga-se de passagem que essa diferença 


\section{4}

de nível implicada pela sensação é que determina o interesse de Bacon pela queda.

Mas por que a "série completa" do corpo sem órgãos na sensação pode ser definida como "realidade histérica do corpo"? Deleuze faz essa aproximação com base nas descrições clássicas da histeria, chegando a dizer que, no "quadro" da histeria tal como ele se forma no século XIX, encontra-se um certo número de caracteres que "não cessam de animar os corpos de Bacon”. Assim, Deleuze afirma que podemos ver o que é descrito em termos de sintomas histéricos no século XIX nas Figuras de Bacon. Assim, na histeria, "a passagem da onda nervosa" se presentifica no corpo sob forma de "contraturas e paralisias", ou, ainda, de "hiperestesias" ou "anestesias", que se associam ou se alternam, que podem ser "fixas" em um órgão ou membro ou "migrantes" (DELEUZE, 1981, p. 35). Em outras palavras, o pintor torna visível a onda nervosa que provoca a sensação encontrando-se com as forças exteriores pintando a ação de ambas sobre os corpos, ao passo que o histérico faz o mesmo em seu corpo, como se sua obra fosse seu corpo. Mas, justamente, fixando-se no corpo, o efeito da onda nervosa não se faz obra, mas patologia. Por isso Rancière assinala a incompatibilidade entre a definição da obra de arte como aquilo que se mantém por si só e a fórmula segundo a qual "com a pintura, a histeria se torna arte. Ou, antes, com o pintor, a histeria se torna pintura" (DELEUZE, 1981, p. 37). A histeria, na sua definição clássica, não seria apenas uma doença mental dentre outras, mas aquela que, por excelência, "opõe-se ao trabalho da obra, que a impede de existir de maneira autônoma, retendo prisioneiras no corpo do artista as potências que deveriam objetivar e autonomizar a obra”. Desse ponto de vista, "a histeria" seria "propriamente a antiobra", uma espécie de "paixão ou efusão nervosa que se opõe à potência atlética e escultural dos músculos" (RANCIÈRE. In: ALLIEZ, 1998, p. 507). Ora, na pintura de Bacon, a histeria torna-se um procedimento de amplificação, de presentificação e de captação do sensível para se exteriorizar na obra, e não mais permanecer interiorizado no corpo.

Nas palavras de Deleuze, "a pintura é histeria, ou converte a histeria, porque ela dá a ver a presença, diretamente”. Ela potencializa as capacidades do olho investindo nele através das "cores" e das "linhas". Contudo, a pintura não trata o olho "como um órgão fixo". De um só golpe, a pintura 
libera "as linhas e as cores da representação" e "o olho de seu pertencimento ao organismo, ela o libera de seu caráter de órgão fixo e qualificado: o olho se torna virtualmente o órgão indeterminado polivalente" (DELEUZE, 1981, p. 37) capaz de aceder ao "corpo sem órgãos, ou seja, à Figura, como pura presença". O olho se torna, então, um órgão migratório, que surge e desaparece por todo lado em nosso corpo, ou como diz Deleuze: “A pintura coloca-nos olhos por toda parte: na orelha, no ventre, nos pulmões (o quadro respira...)". A pintura ganha, assim, uma "dupla definição", subjetiva e objetiva. No polo subjetivo, a pintura "investe nosso olho, que cessa de ser orgânico para se tornar órgão polivalente e transitório". Já no polo objetivo, “ela ergue à nossa frente a realidade de um corpo, linhas e cores liberadas da representação orgânica”. Mas os dois polos estão mutuamente implicados, "um se faz para o outro: a pura presença do corpo será visível, ao mesmo tempo em que o olho será o órgão destinado desta presença”" (DELEUZE, 1981, p. 37).

Assim, a histeria deixa de ser vista como parte do estilo de Bacon para se tornar algo "fundamental" na pintura, ou seja, algo que impulsiona a produção de imagens pictóricas, que é sua relação com a sensação e, portanto, com o corpo. Deleuze considera que essa histerização dos sentidos e do corpo de modo geral subjaz a toda pintura, mas há duas maneiras de pintar que buscam evitá-la, minimizá-la, desviar-se dela. A primeira consiste em "conservar as coordenadas figurativas da representação orgânica, jogando com elas muito sutilmente, fazendo passar sob essas coordenadas ou entre elas presenças liberadas e corpos organizados", é o modo de proceder da arte chamada de clássica. A outra maneira de evitar a "histerização" é "voltar-se para a forma abstrata, e inventar uma cerebralidade propriamente pictural” (DELEUZE, 1981, p. 37).

\footnotetext{
${ }^{1}$ Para os propósitos deste artigo, Rancière figura como leitor de Deleuze, de modo que não se faz necessária uma apresentação das relevantes contribuições de Rancière para o campo da estética.

${ }^{2}$ Todas as citações anteriores estão inseridas neste intervalo.

${ }^{3}$ O termo 'sentente' é utilizado para designar aquele que sente, marcando o caráter reflexivo do sentir (o sujeito sente o objeto ao mesmo tempo que sente a si mesmo no ato mesmo de sentir).
} 
${ }^{4}$ Deleuze se menciona neste ponto- sem citar entre aspas - a seguinte obra: Maldiney, Henry. Regard parole espace. Ed. L'Age de l'homme, pp. 147-172.

\section{Referências bibliográficas}

BUYDENS, M. 2005. Sahara l'esthétique de Gilles Deleuze. Paris:Vrin.

CAVALCANTI, A. S. 2005. Formas e deformação nas pinturas de Francis Bacon: a leitura de Gilles Deleuze. In: ORLANDI, L. B. L. A diferença. Campinas: Editora da Unicamp, pp. 13-26.

DELEUZE, G. 1981. Francis Bacon Logique de la sensation. Paris: La vue Le texte, Édition de La différence.

DELEUZE, G \& GUATTARI, F. 1997. O que é a filosofia? São Paulo: Editora 34.

PACHECO, F.T. 2008. Expressões de Bacon, sensações de Deleuze. Alegrar v. 5, pp. 1-25. (http://www.alegrar.com.br/05/TEXTOS_A_05/ Bacon.pdf)

RANCIÈRE, J. 2000. Existe uma estética deleuzeana? In: ALLIEZ, E. (org.). Gilles Deleuze: uma vida filosófica. São Paulo: Ed. 34, pp. 505-516. SAUVAGNAR GUES, A. 2005. Deleuze et l'art. Paris: PUF. SYLVESTER, D. 2007. Entrevistas com Francis Bacon. São Paulo: Cosac Naify. 


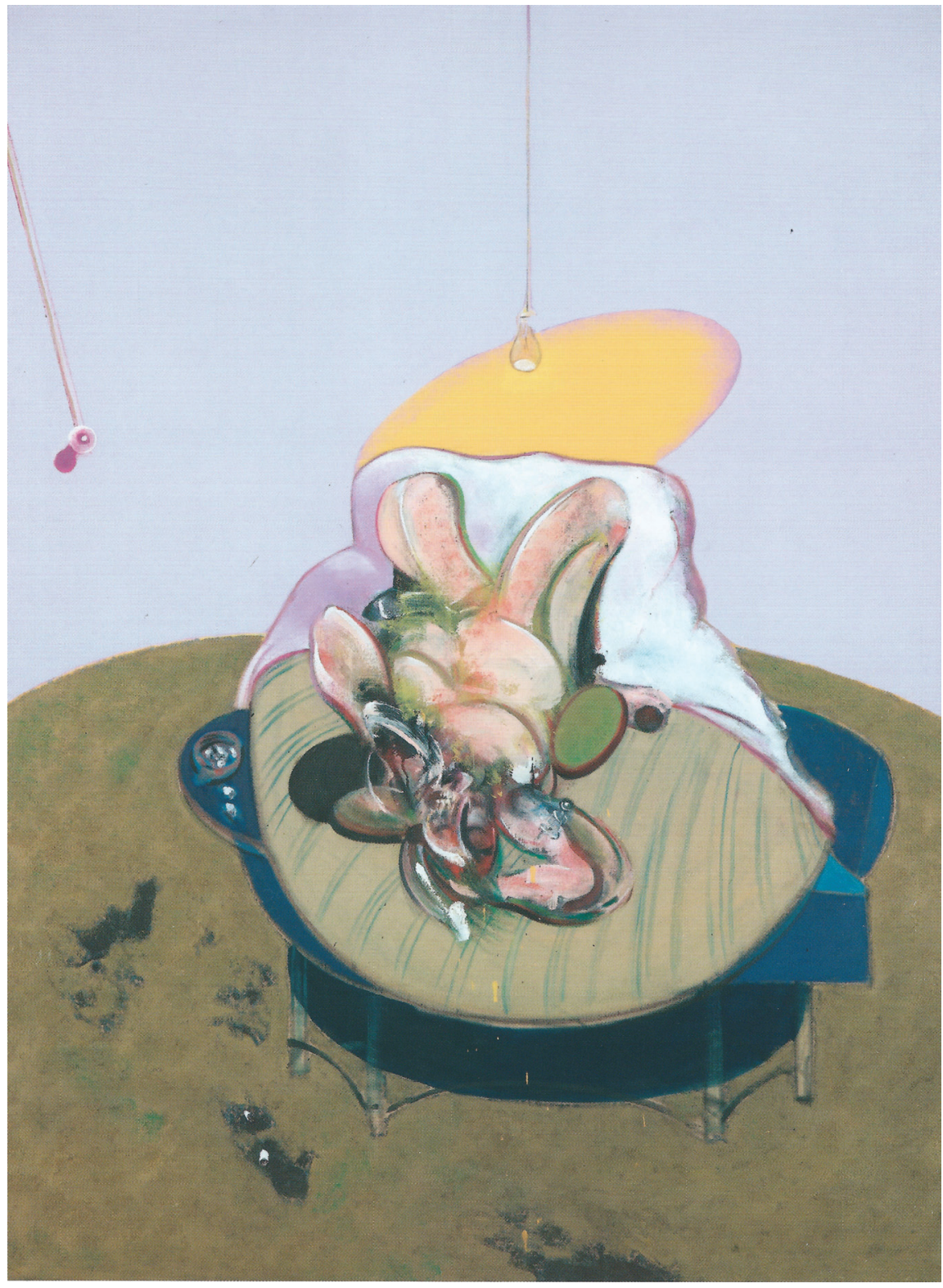

\section{Ilustração 10}

F. Bacon, Lying figure (1969), óleo sobre tela, $198 \mathrm{~cm} \times 147,5 \mathrm{~cm}$. Fondation Beyeler, Riehen/ Basel. 


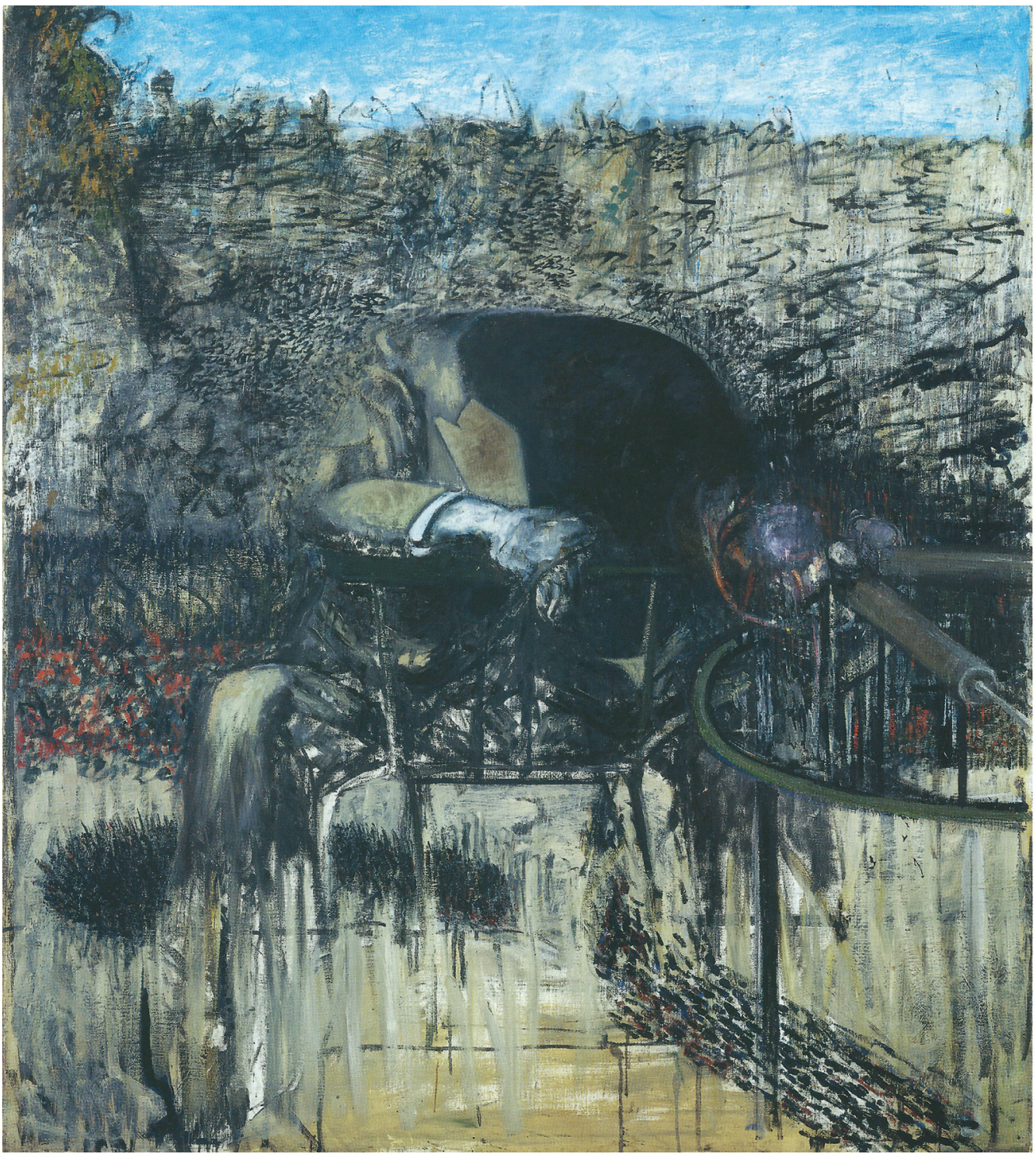

\section{Ilustração 11}

F. Bacon, Figure in a landscape (1945), óleo sobre tela, 144,8cm x 128,3cm, Tate Galery, Londres. 


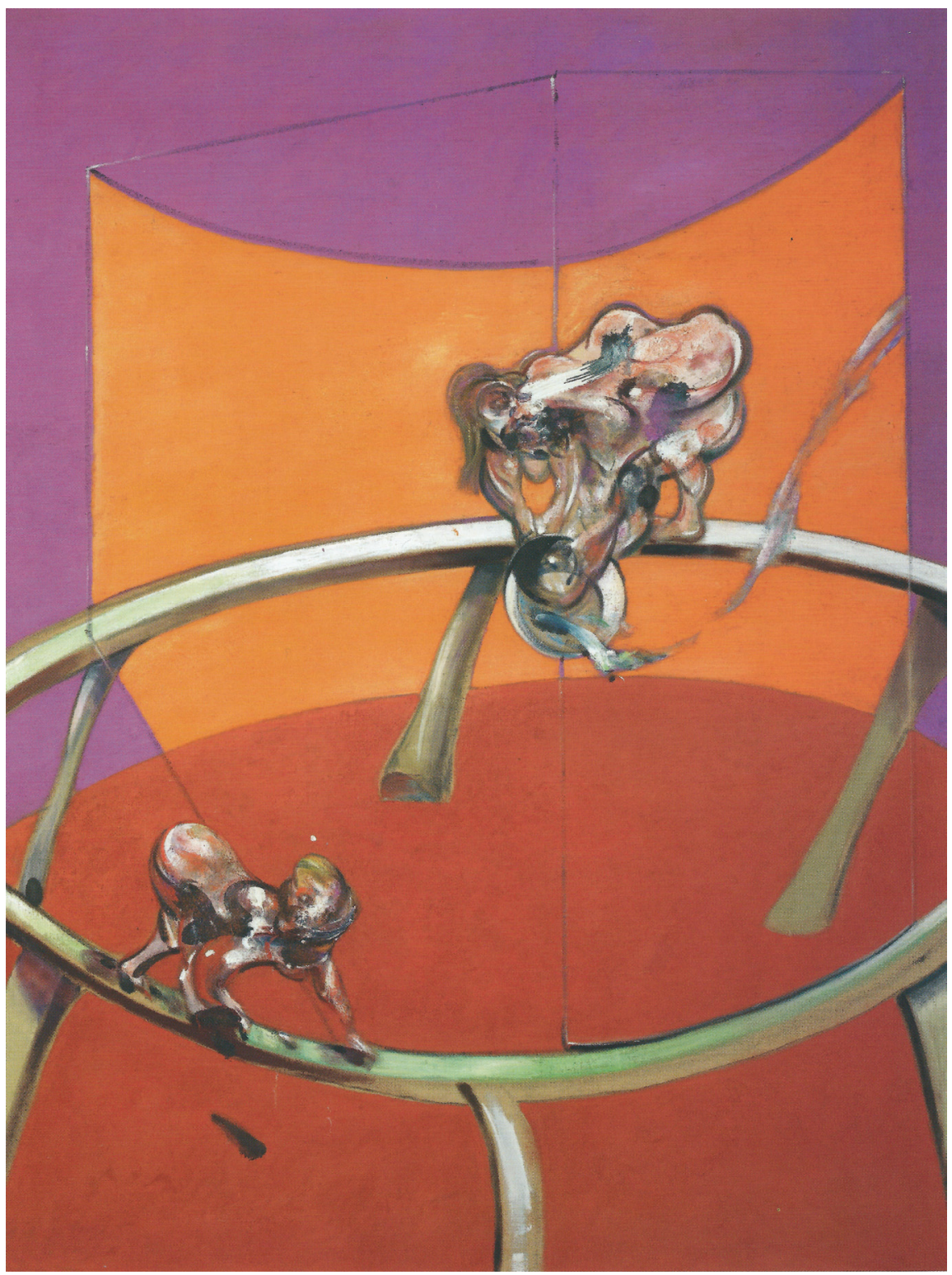

\section{Ilustração 12}

F. Bacon, Figure study I (1945-46), óleo sobre tela, $123 \mathrm{~cm}$ x 105,5cm, Scottish National Gallery of Modern, Edimburgo. 